\title{
3 Research Suare \\ Exploring Professionalism Among Final Year Dental Students and New Graduates: Translating Knowledge To Practice
}

Khaled Khalaf ( $\sim$ kkhalaf@sharjah.ac.ae )

University of Sharjah

Mohamed El-Kishawi

University of Sharjah

Sausan Al Kawas

University of Sharjah

\section{Research Article}

Keywords: Professionalism, dental graduate, knowledge, practice, application, competency

Posted Date: July 21st, 2021

DOl: https://doi.org/10.21203/rs.3.rs-718165/v1

License: (c) (i) This work is licensed under a Creative Commons Attribution 4.0 International License.

Read Full License 


\section{Abstract \\ Background}

Professional competencies are integral part of the competent dental graduate that include professional attitude and behaviour, ethics and communication skills. The aim of this study was to evaluate senior students' and dental graduates' perception of professionalism as defined by international regulatory bodies and to assess students' ability to apply such knowledge in clinical-based scenarios mimicking their daily clinical practice.

\section{Methods}

Knowledge of professional competencies was conducted using a survey based on domains of professionalism for a newly qualified general dental practitioner as defined by international regulatory bodies. This survey consists of 32 items addressing participants' perception of three domains of professionalism. Application of the perceived professional competencies was tested by asking participants to answer questions following the observation of a clinical-based scenario video where participants needed to identify issues related to professional, ethical and communication skills which were embedded in the scenarios.

\section{Results}

Data from 146 participants showed no significant differences in the survey scores between the participants' professional levels, place of practice, age groups and genders. Analyses of correlation between the different domains of professionalism showed significant relationships between pair-wise comparisons of the total domain scores. Paired t-tests revealed that the mean score percentage for each of the three domains of professionalism was significantly higher than the responses reported in the relevant clinical-based scenario questions.

\section{Conclusions}

This indicates that all aspects of professionalism are inter-related and the three domains contributed in a similar way to the overall assessment of professionalism. Furthermore, our findings show that dental practitioners may not be able to apply their knowledge of professionalism in real-life scenarios. This suggests that teaching professionalism at the early stages of the dental curriculum should incorporate innovative approaches to mimic real-life scenarios and should be reinforced throughout clinical practice at the later stages of the curriculum.

\section{Background}


Although it is difficult to have a concrete definition of professionalism as a competency, many have identified common domains that underpins this term in health care provision [1-11]. Specifically in dentistry, several organizations and regulatory bodies worldwide stated that dental graduates are required to have minimum standards of clinical skills as well as soft skills i.e., professionalism and communication skills to adequately perform various procedures during their routine daily dental practice [12-15]. Furthermore, there has been more emphasis in recent years on professionalism as an important attribute to the skills set of a general dental practitioner $[12,13,15,16]$. Clinical skills have long been well taught and assessed in dental curricula [17], but there is no consensus as yet on the teaching and assessment of the soft skills especially professionalism in both undergraduate and postgraduate clinical curricula [18-22]. This is due to the multi-facets nature of this skill especially when interpreted in different cultures, contexts and secular changes in the society [23-25]. Therefore, it is important to develop teaching methods and assessment of professionalism in the contemporary dental curriculum to meet the increased demand of the society and regulatory bodies, with clear and objective learning outcomes in parallel to teaching and assessment of the diagnostic and manual dexterity skills of clinical procedures $[5,26]$.

At University of Sharjah, we have an integrated, competency-based 5 years Bachelor of Dental Surgery (BDS) curriculum. It is a theme-based curriculum with four main themes i.e., Human Biology, Community Dentistry, Dental Health Sciences and Dental Clinical Practice, with the first two themes cease at the second and third years respectively, whereas the other two themes span over the whole curriculum. Ethics and professionalism are mainly taught and assessed as part of the Dental Clinical Practice theme in the final year of the BDS program, using conventional teaching methods and assessments i.e., lectures and written continuous and end of year examinations [27]. In the view of the increasing importance of professionalism as an essential part of the skills set of a newly graduated general dental practitioner and the need to have reciprocity in the teaching and assessment of this skill, we conducted this study with the aim to evaluate our senior students' and dental graduates' perception of professionalism as defined by international regulatory bodies and to introduce a clinical-based scenario video to assess whether our students could apply their prior knowledge of professionalism in their daily clinical practice.

\section{Methods}

\section{Participants}

An ethical approval was granted from the University of Sharjah prior to conducting the study (ethical approval number: REC-19-12-10-01). The main investigator introduced the research project through an email invitation to final year students at College of Dental Medicine, University of Sharjah, UAE; internship students at University of Sharjah, UAE; and graduates of the University of Sharjah, UAE who are either currently enrolled in a master's degree programme or have been working as General Dental Practitioners (GDPs). All participants were provided with information sheets and consent forms to voluntarily take part in the study. As a result, a total of 146 participants (33 final year BDS students, 30 interns, 9 graduate students, and 74 GDPs) were consented to participate in the study. 


\section{Professional competency knowledge survey}

Knowledge of professional competencies was conducted using a survey based on domains of professionalism deemed to be necessary for a newly qualified general dental practitioner in the USA, Australia, Canada, Europe and Pakistan $[2,12,28,29]$.

This survey (Appendix 1) consists of 32 items that are rated on a five-point Likert scale from 1 (strongly disagree), 2 (disagree), 3 (not sure), 4 (agree) and 5 (strongly agree). These items address participants' perception of three domains of professionalism under which were grouped 32 competencies as follows; 9 for Professional Attitude and Behaviour (PAB), 15 for Ethics and Jurisprudence (EJ), and 8 for Communication and Interpersonal Skills (CIS). A pilot study was carried out by delivering the questionnaire to 25 randomly selected dental graduates to test the clarity, comprehension and the feasibility of completing the questionnaire in a reasonable time frame. Subsequently, it was found that all items of the questionnaire were clear and meaningful to participants following a minor revision being made to some items. Moreover, it was found that participants require, on average, 13 minutes to complete the questionnaire. Furthermore, the survey has shown good internal reliability (Cronbach alpha of 0.87 . Data on participants' personal characteristics and demographic data, i.e., age, gender, year of graduation, professional level and type of institution/ employer were also collected. An overall score for each individual was calculated by assigning a value of 1 for "strongly disagree", 2 for "disagree", 3 for "not sure", 4 for "agree" and 5 for "strongly agree"; and percentages of these scores were then summed.

\section{Application of professional competency knowledge/ clinical-based scenario questions}

Application of the perceived professional competencies was tested by creating a clinical-based scenario video (Appendix 2) where dental practitioners needed to apply previously learned professional, ethical and communication skills. We asked participants who completed the knowledge survey to answer 5 questions related to the video, of which two were related to professional attitude and behaviour (question 3 which is called application 1 of the domain and question 4 which is called application 2 of the domain), two questions were related to ethics and Jurisprudence (question 1 which is called application 1 of the domain and question 2 which is called application 2 of the domain), and one question related to communication and Interpersonal Skills (question 5 which is called application 1 of the domain). The 5 questions were single best answer questions, but with a hierarchy of level of plausibility (Table 3). They were written by two experts in dental education and further reviewed by a panel of clinical academics who had interest and significant experience in dental education. An overall score for each participant was calculated by assigning a value from 1 to 5 from the least to the most accurate/ plausible response, and percentages of these scores were then summed.

\section{Data Analysis}


All data were coded prior to data analysis. Tests of normality were performed where appropriate using normal probability plots [30] and equal variance tests [31]. Percentages of responses and the overall score for each individual were calculated. Mean values and standard deviations of the surveys were calculated according to the method described by Field (2009) [32]. Internal consistency reliability was assessed by Cronbach alpha (a) [33]. Pearson product-moment correlations were used to test the association between scores of the surveys. Analysis of variance (ANOVA), with post-hoc analyses and student's t-test as appropriate, were used to assess the effect of differences in gender, professional level, place of practice and age groups on the outcome survey scores within the three domains of the knowledge survey. Students' t-tests were used to assess whether there were statistically significant differences in score percentages between each of the perceived domain of professionalism and the responses to the clinical scenario video questions relevant to that domain. All data analyses were conducted using SPSS (version 26.0; SPSS Inc, Chicago, IL), and statistical significance for quantitative and categorical data was set at $p<0.05$. Responses from the open-ended questions were analyzed using a thematic analysis method as described by Braun and Clarke [34].

\section{Results}

Data from 146 participants (41 males and 105 females) were available for analyses. Participation response rate was 75\%. Participants' ages ranged from 22-33 years (mean age and standard deviation: $25.64 \pm 2.43$ years). Participants' professional level varied between final year dental students $(23 \%)$, internship dental graduates (20\%), post graduate students (6\%), and general dental practitioners (51\%) graduated from the University of Sharjah (Table 1). The majority of participants were Arabs (90\%), and the remaining minority $(10 \%)$ were either Persian, Indian, or Pakistani. 
Table 1

Survey scores (percentages) of the three professional domains (PAB, EJ, and CIS) Means (and Standard Deviations) of participants by Gender,

Professional Level, Place of Practice and Age Group. PAB = Professional Attitude and Behaviour, EJ = Ethics and Jurisprudence, and $\mathrm{CIS}=$ Communication and Interpersonal Skills.

\begin{tabular}{|c|c|c|c|c|}
\hline & & PAB & EJ & CIS \\
\hline & $\mathbf{N}$ & $M(S D)$ & $M(S D)$ & $M(S D)$ \\
\hline \multicolumn{5}{|l|}{ Gender } \\
\hline Male & 41 & $89.60(8.51)$ & $90.80(8.41)$ & 89.51 (9.05) \\
\hline Female & 105 & $90.29(9.34)$ & $89.29(10.95)$ & 87.79 (12.82) \\
\hline \multicolumn{5}{|c|}{ Professional Level } \\
\hline BDS5 & 33 & $90.91(8.74)$ & $91.07(9.68)$ & 89.85 (9.29) \\
\hline Intern & 30 & $88.74(9.78)$ & 85.73 (12.49) & $85.83(13.51)$ \\
\hline Post Grad & 9 & $88.89(11.17)$ & $92.73(8.78)$ & $89.44(10.95)$ \\
\hline GP & 74 & $90.42(8.82)$ & $90.36(9.49)$ & 88.41 (12.38) \\
\hline \multicolumn{5}{|l|}{ Place of Practice } \\
\hline UDHS & 75 & $89.51(9.14)$ & $88.44(10.78)$ & $87.60(11.30)$ \\
\hline Private Practice & 49 & $90.43(8.59)$ & $90.40(9.04)$ & $88.52(10.58)$ \\
\hline UDHS \& Private & 7 & $93.34(8.60)$ & $94.47(6.50)$ & $95.00(5.20)$ \\
\hline Unemployed & 5 & $91.12(8.48)$ & $93.34(8.75)$ & $90.00(10.75)$ \\
\hline Academic & 4 & 92.78 (8.78) & $95.65(5.28)$ & $91.25(11.81)$ \\
\hline Government & 6 & $88.13(15.13)$ & $87.55(18.25)$ & $83.33(28.45)$ \\
\hline \multicolumn{5}{|l|}{ Age Group } \\
\hline$<25$ & 53 & $91.78(8.84)$ & $91.37(9.24)$ & $89.86(9.97)$ \\
\hline $25-26$ & 50 & 89.34 (8.95) & $88.93(11.45)$ & $87.80(12.31)$ \\
\hline$>26$ & 43 & $88.89(9.46)$ & 88.58 (10.09) & $86.86(13.50)$ \\
\hline
\end{tabular}

\section{Responses to the knowledge survey}

The professionalism competency survey had an excellent internal reliability (Cronbach alpha of 0.97). Responses to individual items within the scale ranged from $0-80 \%$ (Table 2). It was clear that the majority of participants responded with the "strongly agree" and "agree" categories within the three domains in this survey. ANOVA analysis showed no statistically significant differences in survey scores 
between professional levels, place of practice and age groups (Table 1). Similarly, no statistically significant differences in the survey scores were found between genders. Analyses of correlation between the different domains of professionalism showed statistically significant relationships between the total domain scores for the PAB and EJ $(r(146)=0.83, p<0.001)$, the PAB and CIS $(r(146)=0.81, p<0.001)$, and the EJ and $\mathrm{CIS}(r(146)=0.86, p<0.001)$. 
Table 2

Participants' ' perception on professional competencies in dentistry.

\section{Questions}

\%SA \%A \%N

$\% \mathrm{D} \quad \% \mathrm{SD}$

A) Professional Attitude and Behaviour

1) Displaying appropriate caring behaviour towards patients $\quad \begin{array}{lllllll}80 & 19 & 1 & 0 & 0\end{array}$ and showing willingness to help

2) Displaying professional behaviour towards all members of $\begin{array}{llllll}77 & 22 & 1 & 0 & 0\end{array}$ the dental team

3) Have knowledge of the management of a dental practice 55

4) Deal with other members of the dental team with regard to $\begin{array}{lllllll}64 & 32 & 4 & 0 & 0\end{array}$ health and safety

5) Have knowledge of the importance of health in relation to $\begin{array}{lllllll}58 & 36 & 6 & 0 & 0\end{array}$ occupational hazards and its impact

6) Have knowledge of the Social and psychological issues relevant to the care of patients

7) The management of a dental practice, patient communication and able to oversee financial aspects of practice

8) Managing and maintaining a safe working environment

$\begin{array}{lllll}65 & 33 & 2 & 0 & 0\end{array}$

9) Seeking continuing professional development (CPD) on an $\begin{array}{llllll}40 & 42 & 15 & 3 & 0\end{array}$ annual basis, demonstrated through portfolio/CPD Logbook

$\begin{array}{lllll}51 & 40 & 8 & 1 & 0\end{array}$

$\begin{array}{lllll}49 & 33 & 14 & 3 & 1\end{array}$

Ethics and Jurisprudence

10) Providing humane and compassionate care to all patients $\begin{array}{lllllll}70 & 26 & 3 & 1 & 0\end{array}$

11) Practicing with personal and professional integrity, $\quad \begin{array}{lllllll}71 & 26 & 2 & 1 & 0\end{array}$ honesty and trustworthiness.

12) Respecting patients and colleagues without prejudice $\quad \begin{array}{llllll}70 & 24 & 4 & 1 & 1\end{array}$ concerning gender, diversity of background opportunity, language, culture, disabilities and sexual orientation

13) Recognizing their own limitations

$\begin{array}{lllll}58 & 38 & 3 & 1 & 0\end{array}$

14) Producing and maintaining an accurate patient record and record of patient treatment

$\begin{array}{lllll}66 & 30 & 3 & 1 & 0\end{array}$

15) Selecting and prioritizing treatment options that are sensitive to each patient

$\begin{array}{lllll}62 & 33 & 5 & 0 & 0\end{array}$

$\% \mathrm{SA}=$ Percentage of strongly agree response, $\% \mathrm{~A}=$ Percentage of agree response, $\% \mathrm{~N}=$ Percentage of neutral response, \%D = Percentage of disagree response, and \%SD = Percentage of strongly disagree response. 


\section{Questions}

16) Recognizing patients' rights, particularly with regard to confidentiality, informed consent, and patients' obligations

17) Have knowledge of the ethical principles relevant to dentistry

18) Acknowledging that the patient is the center of care and that all interactions, including diagnosis, treatment planning and treatment, must focus on the patient's best interests

19) Have knowledge of the fact that dentists should strive to provide the highest possible quality of patient care in variety of circumstances

20) Taking action that is audit and clinical governance to ensure quality of care

21) Selecting and prioritizing patient's individual needs, goals and values, compatible with contemporary methods of treatment, and congruent with an appropriate oral health care philosophy.

22) Have knowledge of the socio-economic inequities and inequalities in oral health.

23) Taking appropriate action to help the incompetent, impaired or unethical colleague and their patients

24) Have knowledge of the judicial, legislative and administrative processes and policy that impact all aspects of dentistry

\section{C) Communication and Interpersonal Skills}

25) Establishing a patient-dentist relationship that allows the effective delivery of dental treatment including, when appropriate a relationship with a parent or carer

26) Identifying patient expectations, desires and attitudes (needs and demands) when considering treatment planning and during treatment

27)

Sharing information and professional knowledge with the patient

28) Identifying the psychological and social factors that and dysfunction and diagnose, treat or refer, as appropriate initiate and/or perpetuate dental, oral and facial disease

\section{\%SA $\quad \% A \quad \% N \quad \% D \quad \% S D$}

69

$\begin{array}{llll}27 & 3 & 1 & 0\end{array}$

$\begin{array}{lllll}60 & 36 & 3 & 1 & 0\end{array}$

66

$\begin{array}{llll}30 & 3 & 1 & 0\end{array}$

$\begin{array}{lllll}60 & 36 & 3 & 1 & 0\end{array}$

45

$43 \quad 10 \quad 1$

1

52

40

$\begin{array}{lll}6 & 1 & 1\end{array}$

$\begin{array}{lllll}42 & 45 & 11 & 2 & 0\end{array}$

$\begin{array}{lllll}43 & 40 & 14 & 2 & 1\end{array}$

$\begin{array}{lllll}41 & 34 & 21 & 3 & 1\end{array}$

$\begin{array}{lllll}53 & 38 & 8 & 1 & 0\end{array}$




\begin{tabular}{|c|c|c|c|c|c|c|}
\hline & Questions & \%SA & $\% A$ & $\% N$ & $\% \mathrm{D}$ & $\% S D$ \\
\hline 29) & $\begin{array}{l}\text { Have knowledge of the behavioural sciences including } \\
\text { behavioural factors (including factors such as ethnicity } \\
\text { and gender) that facilitate the delivery of dental care }\end{array}$ & 48 & 40 & 9 & 2 & 1 \\
\hline 30) & $\begin{array}{l}\text { Have knowledge of the role and the stages of the } \\
\text { intellectual, social-emotional and language development } \\
\text { of children and adolescence }\end{array}$ & 45 & 45 & 9 & 1 & 0 \\
\hline 31) & $\begin{array}{l}\text { Applying principals of stress management to oneself, to } \\
\text { patients and to the dental team as appropriate }\end{array}$ & 50 & 38 & 9 & 3 & 0 \\
\hline 32) & $\begin{array}{l}\text { Communicating with other doctors and health } \\
\text { professionals, verbally and in writing including being able } \\
\text { to receive and give constructive criticism }\end{array}$ & 46 & 40 & 9 & 4 & 1 \\
\hline
\end{tabular}

\section{Responses to the application of knowledge questions}

Mean score percentages of the correct answers to the five questions ranged from 35.1 to 87.1. The percentages of participants who answered each option related to the clinical-based scenario video ranged from 1.1-97.7\% (Table 3). Paired t-tests were used to assess whether there were statistically significant differences in the mean knowledge/ perception survey scores of the three domains of professionalism (PAB, EJ, and CIS) and the response scores to their relevant clinical scenario video questions (applications 1 \& 2) (Fig. 1). Paired t-tests revealed that the mean score percentage for the PAB domain was significantly higher than that of question $3(t(60)=3.16, p=0.002)$, and question $4(t(60)=9.22, p<$ $0.001)$. The mean score percentage for the responses reported for question 2 was significantly lower than the mean score perception reported in the EJ domain $(t(60)=21.32, p<0.001)$. Similarly, the mean score percentage for the responses reported for question 5 was significantly lower than the CIS domain mean score $(t(60)=25.95, p<0.001)$. 
Table 3

Mean score percentages and (standard deviation) of the correct answers to the five questions and the percentages of participants who answered each option related to the clinical-based scenario video.

\section{Questions and answers (scores)}

A) Professional Attitude and Behaviour

Q 3.

Displaying appropriate caring behaviour towards patients and

Application

a. Dr Amel was emotional in her conversation with Dr Shareef (2)

35.6

1

b. Dr Shareef had an insight into his behavior, but thought the matter

60.9 was trivial (4)

c. Dr. Shareef admitted his mistake and showed remorse (1)

0

d. Dr Shareef's behavior can lead to disciplinary action (3)

3.5

Q 4.

Displaying professional behaviour towards all members of the dental team

${ }_{2}^{\text {Application }}$

a. It is determined that this incident was an isolated one, (4)

16.1

b. Dr. Shareef appreciates the significance of his actions (3)

29.9

c. Dr Shareef takes steps to change his behavior (2)

8.0

d. Dr Amal has concern that Dr Shareef may raise the matter to her line manager (1)

46.0

Ethics and Jurisprudence

B)

Q 1.

How should Dr. Ahmed respond to the question: "Do you have a problem with that?

Application

a. Say "no" and walk away (1)

1

b. Apologize and walk away (2)

c. Tell Dr. Shareef the patient's story (3)

d. Say something about the rules regarding patient confidentiality

53.4 (5)

e. Explore other options around how to discuss the rules and regulations of patient confidentiality with a colleague or chief of staff (4)

Q 2.

Is Dr. Shareef's response appropriate from an ethical point of view?

\section{2}

b. No, the reason he gave for accessing the chart in the first place (2) 


\begin{tabular}{|c|c|c|c|}
\hline & Questions and answers (scores) & $\%$ & $\begin{array}{l}M \\
(S D)\end{array}$ \\
\hline C) & Communication and Interpersonal Skills & & \\
\hline Q 5. & $\begin{array}{l}\text { Establishing a patient-dentist relationship that allows the effective } \\
\text { delivery of dental treatment including, when appropriate a } \\
\text { relationship with a parent or carer }\end{array}$ & & $\begin{array}{l}35.06 \\
(12.33)\end{array}$ \\
\hline \multirow[t]{4}{*}{$\begin{array}{l}\text { Application } \\
1\end{array}$} & $\begin{array}{l}\text { a. This action generalizes the problem and allows others to benefit. } \\
\text { (4) }\end{array}$ & 0 & \\
\hline & $\begin{array}{l}\text { b. This course of action might help Dr. Shareef to view the } \\
\text { conversation in a more positive light (3) }\end{array}$ & 0 & \\
\hline & $\begin{array}{l}\text { c. Dr Amal decided to let people know that Dr Shareef has such a } \\
\text { behavior (1) }\end{array}$ & 59.8 & \\
\hline & $\begin{array}{l}\text { d. This action will serve as an apology from Dr Shareef to Dr Ahmed } \\
\text { in public (2) }\end{array}$ & 40.2 & \\
\hline
\end{tabular}

\section{Thematic analysis of participants' responses to the open- ended questions}

Seventy-eight out of 88 (89\%) of the participants responded to the question explain your answer to "how should the clinician responsible for patient's care respond to the question: "Do you have a problem with that?". Most participants explained that the supervisor in the scenario was breaching patient's confidentiality by checking the patient's personal details and dental records. The second reported explanation was unprofessional behaviour and the aggressive attitude by the supervisor towards the intern. It was also mentioned that the supervisor must have proper consent and permission from the patient to access their details (Table 4). 
Table 4

Thematic analysis of participants' response to the open-ended question.

\begin{tabular}{|c|c|c|c|}
\hline \# & Themes & Subthemes & Quotations \\
\hline \multirow[t]{4}{*}{1} & \multirow[t]{4}{*}{$\begin{array}{l}\text { Patient's } \\
\text { Confidentiality }\end{array}$} & $\begin{array}{l}\text { - Crossing } \\
\text { patient } \\
\text { confidentiality }\end{array}$ & $\begin{array}{l}\text { "He is crossing the patient confidentiality in two ways: He is } \\
\text { checking a patient dental record who is not registered under } \\
\text { his name and is discussing the reason for that with others" }\end{array}$ \\
\hline & & $\begin{array}{l}\text { - Using } \\
\text { patient details } \\
\text { for personal } \\
\text { reason }\end{array}$ & $\begin{array}{l}\text { "Dr Shareef is using patients own details that are very } \\
\text { confidential in the hospital for his own personal life, in } \\
\text { addition to that he is sharing the patient's personal info with } \\
\text { another colleague and that is unethical" }\end{array}$ \\
\hline & & \multirow{2}{*}{$\begin{array}{l}\text { - Violating } \\
\text { rules and not } \\
\text { respecting } \\
\text { confidentiality }\end{array}$} & $\begin{array}{l}\text { "The Dr is violating the rules and regulations and patient } \\
\text { confidentiality which is unethical" }\end{array}$ \\
\hline & & & “He must respect patient's confidentiality" \\
\hline \multirow[t]{4}{*}{2} & \multirow[t]{4}{*}{$\begin{array}{l}\text { Professional } \\
\text { Attitude and } \\
\text { Behaviour }\end{array}$} & $\begin{array}{l}\text { - Not } \\
\text { appropriate } \\
\text { behaviour in }\end{array}$ & \multirow{2}{*}{$\begin{array}{l}\text { "The language (as well as the body language he expressed) } \\
\text { and his tone is not suitable and professional for a clinic } \\
\text { setting" } \\
\text { "he shouldn't respond to the intern with an aggressive tone } \\
\text { and he should show mutual respect" }\end{array}$} \\
\hline & & \multirow{2}{*}{$\begin{array}{l}\text { - Lack of } \\
\text { respect for } \\
\text { intern }\end{array}$} & \\
\hline & & & "He should be more polite and have better attitude" \\
\hline & & $\begin{array}{l}\text { - Not suitable } \\
\text { behaviour }\end{array}$ & "Aggressive and disrespectful" \\
\hline \multirow[t]{4}{*}{3} & \multirow[t]{4}{*}{$\begin{array}{l}\text { Patient's } \\
\text { Consent }\end{array}$} & \multirow{2}{*}{$\begin{array}{l}\text { - Not taking } \\
\text { permission } \\
\text { from institute } \\
\text { or colleagues }\end{array}$} & $\begin{array}{l}\text { "Dr Shareef should take permission from the doctor who is } \\
\text { treating that patient" }\end{array}$ \\
\hline & & & $\begin{array}{l}\text { "He does not have a proper appointment date and wasn't } \\
\text { assigned for that patient" }\end{array}$ \\
\hline & & $\begin{array}{l}\cdot \text { No consent } \\
\text { from patient }\end{array}$ & \multirow{2}{*}{$\begin{array}{l}\text { "IF the patient is not your patient and you want to read their } \\
\text { file you must have at the very least the consent of said } \\
\text { patient" }\end{array}$} \\
\hline & & $\begin{array}{l}\text { - Violation of } \\
\text { rules and } \\
\text { regulations }\end{array}$ & \\
\hline
\end{tabular}

\section{Discussion}

The majority of participants responded with the "strongly agree" and "agree" categories within the three domains of the professionalism perception competency survey, indicating that the participants perceived all items of professionalism to be important, regardless of their professional levels, place of practice, age and gender. In our study, the ranges of participants' responses to the three domains of professionalism survey i.e., "professional attitude and behavior: PAB", "ethics and jurisprudence: EJ" and "communication and interpersonal skills: CIS" were 82-99\%, 75-98\% and 86-98\% respectively. These were higher than what was reported in a previous investigation of perception of professionalism among 386 dental graduates of eight public- and private-sector dental colleges in Pakistan [29], where the corresponding figures to those in our study were $51-99 \%, 60-97 \%$ and $61-91 \%$. The differences between our findings 
and those reported in the aforementioned study may be attributed to the differences in teaching and application of the professionalism subject in the BDS curricula. Further support to this explanation can be inferred from previous investigations which showed inadequate infection control practices among senior faculty members in Karachi, Pakistan [35] as compared to their prior knowledge of such measures, and the high prevalence of musculoskeletal disorders among general dental practitioners in Pakistan which is most probably due to poor teaching and application of proper ergonomics during their BDS programme [36]. Furthermore, many dental curricula in developing country may not prepare their students to work well in disadvantaged populations with special oral health needs [37]. It is part of our dental curriculum to make our students fully aware of the factors that impact on oral health needs of the community including socio-economic inequities. Furthermore, we have a mobile dental clinic with regular students' allocation to serve the rural, elderly, and disadvantaged populations.

In our study, participants did not consider maintaining Continuing Professional Development (CPD) as important as the other items of the PAB domain. This is due to the need to invest a lot of time and money in activities which may not be considered as important especially those that were deemed noncompulsory by regulatory bodies $[29,38]$.

The item which was considered by our participants as the least important among all domains of professionalism was "have knowledge of the judicial, legislative and administrative processes and policy that impact all aspects of dentistry". A similar finding was also reported in previous studies [29, 39], which may be attributed to the lack of a formally structured and taught course addressing ethics and legal issues in many dental curricula [40].

Looking closely at the responses to the items within each domain, in the "PAB" domain, items that were considered most important by participants were "displaying appropriate caring behaviour towards patients and showing willingness to help" and "displaying professional behaviour towards all members of the dental team", whereas the item which was deemed the least important was "seeking continuing professional development (CPD) on an annual basis, demonstrated through portfolio/CPD Logbook". In the "EJ" domain, participants considered "providing humane and compassionate care to all patients" and "practicing with personal and professional integrity, honesty and trustworthiness" as the most important items, whereas the item "have knowledge of the judicial, legislative and administrative processes and policy that impact all aspects of dentistry" was considered as the least important one. In the "CIS" domain the items "establishing a patient-dentist relationship that allows the effective delivery of dental treatment including, when appropriate a relationship with a parent or carer" and "identifying patient expectations, desires and attitudes (needs and demands) when considering treatment planning and during treatment" were deemed by participants as the most important ones, whereas, the item "communicating with other doctors and health professionals, verbally and in writing including being able to receive and give constructive criticism" was considered as the least important item. The above findings agree with Chaudhry et al. study [29] where a similar pattern of importance was also reported by their participants. 
The Correlation between the different domains of professionalism showed significant relationships between the total domain scores for the PAB and EJ, the PAB and CIS, and the EJ and CIS $(p<0.001)$. This indicates that all domains of professionalism are inter-related and if participants have a good knowledge of one domain, they are very likely to be good at the remaining domains of professionalism. Furthermore, this provides an evidence to the appropriate use of the questionnaire as the three domains contributed in a similar way to the overall assessment of professionalism.

In order to investigate the relationship between knowledge and practice of professionalism, a correlation was tested between the mean of the three professional domains (PAB, EJ, and CIS) and their relevant response scores (applications 1 \& 2). It was found that the mean score percentage for the PAB domain was significantly higher than the responses reported in question 3 and 4 which were meant to test the application of the knowledge in the PAB domain. This means that participants' knowledge of the PAB domain was significantly better than their application of such knowledge when tested in clinical practice. Similarly, participants' knowledge of the EJ and CIS domains were significantly better than their application of such knowledge. These differences between the knowledge of the three domains of professionalism and their application in clinical practice suggest that teaching professionalism should start with a cognitive base, reinforced through case-based scenarios, and internalized throughout the clinical practice phase of the curriculum (experiential learning) [41]. This necessitates a strong support of the teaching of professionalism throughout the educational program.

\section{Conclusions}

- All aspects of professionalism are interrelated and the three domains contributed in a similar way to the overall assessment of professionalism.

- Dental practitioners may not be able to apply their knowledge of professionalism in real-life scenarios.

- Teaching professionalism at the early stages of the curriculum should incorporate innovative approaches to mimic real-life scenarios and should be reinforced throughout clinical practice at the later stages of the curriculum.

\section{Abbreviations}

BDS: Bachelor of Dental Surgery; GDPs: General Dental Practitioners; PAB: Professional Attitude and Behaviour; EJ: Ethics and Jurisprudence; CIS: Communication and Interpersonal Skills; CPD: Continuing Professional Development.

\section{Declarations}

\section{Ethics approval and consent to participate}


An ethical approval was granted from the University of Sharjah prior to conducting the study (ethical approval number: REC-19-12-10-01). All participants were provided with information sheets and consent forms to voluntarily take part in the study.

\section{Consent for publication}

Not applicable

\section{Availability of data and materials}

The datasets used and/or analysed during the current study are available from the corresponding author on reasonable request.

\section{Competing interests}

The authors declare that they have no competing interests

\section{Funding}

There are no sources of funding nor any conflicts of interest.

\section{Authors' contributions}

KK: literature review concept design, analysis and interpretation of data, drafting of manuscript. ME: analysis and interpretation of data, drafting of manuscript. SK: analysis and interpretation of data, drafting of manuscript.

All authors read and approved the final manuscript.

\section{Acknowledgements}

Not applicable

\section{References}

1. Plasschaert A, Boyd M, Andrieu S, Basker R, Beltran RJ, Blasi G, Chadwick B, Chambers D, Christersson C, Haddock F et al: 1.3 Development of professional competences. Eur J Dent Educ 2002, 6 Suppl 3:33-44.

2. Physicians WPotRCo: Doctors in society. Medical professionalism in a changing world. Clin Med 2005, 5(6 Suppl 1):S5-40.

3. van Mook WN, de Grave WS, Wass V, O'Sullivan H, Zwaveling JH, Schuwirth LW, van der Vleuten CP: Professionalism: evolution of the concept. Eur J Intern Med 2009, 20(4):e81-84. 
4. Council GD: Preparing for practice: Dental team learning outcomes for registration (2015 revised edition). In. London: GDC; 2015: 1-104.

5. Arnold L: Assessing professional behavior: yesterday, today, and tomorrow. Acad Med 2002, 77(6):502-515.

6. Jha V, Bekker HL, Duffy SR, Roberts TE: Perceptions of professionalism in medicine: a qualitative study. Med Educ 2006, 40(10):1027-1036.

7. Van De Camp K, Vernooij-Dassen MJ, Grol RP, Bottema BJ: How to conceptualize professionalism: a qualitative study. Med Teach 2004, 26(8):696-702.

8. Welie JV: Is dentistry a profession? Part 1. Professionalism defined. J Can Dent Assoc 2004, 70(8):529-532.

9. Welie JV: Is dentistry a profession? Part 2. The hallmarks of professionalism. J Can Dent Assoc 2004, 70(9):599-602.

10. Zijlstra-Shaw S, Robinson PG, Roberts T: Assessing professionalism within dental education; the need for a definition. Eur J Dent Educ 2012, 16(1):e128-136.

11. Bateman $\mathrm{H}$, Ellis J, McCracken G: Professionalism in undergraduate dental education: a pause for thought. Br Dent J 2019, 227(12):1025-1027.

12. Cowpe J, Plasschaert A, Harzer W, Vinkka-Puhakka H, Walmsley AD: Profile and competences for the graduating European dentist - update 2009. Eur J Dent Educ 2010, 14(4):193-202.

13. Plasschaert AJ, Holbrook WP, Delap E, Martinez C, Walmsley AD: Profile and competences for the European dentist. Eur J Dent Educ 2005, 9(3):98-107.

14. ADEA: Competencies for the New General Dentist: (As approved by the 2008 ADEA House of Delegates). J Dent Educ 2017, 81(7):844-847.

15. Council GD: Shifting the balance: a better, fairer system of dental regulation 2017. In. London, UK: General Dental Council; 2017: 1-64.

16. Brown G, Manogue M, Rohlin M: Assessing attitudes in dental education: is it worthwhile? Br Dent J 2002, 193(12):703-707.

17. Khalaf K, El-Kishawi M, Mustafa S, Al Kawas S: Effectiveness of technology-enhanced teaching and assessment methods of undergraduate preclinical dental skills: a systematic review of randomized controlled clinical trials. BMC Med Educ 2020, 20(1):286.

18. Hodges BD, Ginsburg S, Cruess R, Cruess S, Delport R, Hafferty F, Ho MJ, Holmboe E, Holtman M, Ohbu $S$ et al: Assessment of professionalism: recommendations from the Ottawa 2010 Conference. Med Teach 2011, 33(5):354-363.

19. Ginsburg S, Regehr G, Lingard L: Basing the evaluation of professionalism on observable behaviors: a cautionary tale. Acad Med 2004, 79(10 Suppl):S1-4.

20. Cruess RL: Teaching Professionalism: Theory, Principles, and Practices. Clin Orthop Relat Res 2006, 449:177-185. 
21. O'Sullivan H, van Mook W, Fewtrell R, Wass V: Integrating professionalism into the curriculum: AMEE Guide No. 61. Med Teach 2012, 34(2):e64-77.

22. Rees CE, Knight LV: The trouble with assessing students' professionalism: theoretical insights from sociocognitive psychology. Acad Med 2007, 82(1):46-50.

23. Martimianakis MA, Maniate JM, Hodges BD: Sociological interpretations of professionalism. Med Educ 2009, 43(9):829-837.

24. van Mook WN, van Luijk SJ, O'Sullivan H, Wass V, Harm Zwaveling J, Schuwirth LW, van der Vleuten $\mathrm{CP}$ : The concepts of professionalism and professional behaviour: conflicts in both definition and learning outcomes. Eur J Intern Med 2009, 20(4):e85-89.

25. Evetts J: The Sociological Analysis of Professionalism: Occupational Change in the Modern World. Int Sociol 2003, 18(2):395-415.

26. Ranauta A, Freeth $D$, Davenport E: Developing understanding and enactment of professionalism: undergraduate dental students' perceptions of influential experiences in this process. Br Dent $\mathrm{J} 2018$, 225(7):662-666.

27. Khalaf K, El-Kishawi M, Moufti MA, Al Kawas S: Introducing a comprehensive high-stake online exam to final-year dental students during the COVID-19 pandemic and evaluation of its effectiveness. Med Educ Online 2020, 25(1):1-10.

28. Gerrow JD, Chambers DW, Henderson BJ, Boyd MA: Competencies for a beginning dental practitioner in Canada. J Can Dent Assoc 1998, 64(2):94-97.

29. Choudhry S, Yasmeen R, Hossain Bokhari SA, Wajid G, Khan AA: Dental graduates perspective of professionalism competences from a developing country. J Pak Med Assoc 2017, 67(9):1339-1345.

30. Wilk M, Gnanadesikan R: Probability plotting methods for the analysis of data. Biometrika 1968, 55(1):1-17.

31. Shapiro S, Wilk M: An analysis of variance test for normality (complete samples). Biometrika 1965, 52(3/4):591-611.

32. Field A: Discovering statistics using SPSS: (and sex, drugs and rock ' $n$ ' roll), 3rd edn. Los Angeles: SAGE Publications; 2009.

33. Cook D, Beckman T: Current concepts in validity and reliability for psychometric instruments: theory and application. Am J Med 2006, 119(2):166 e167-116.

34. Braun V, Clarke V: Using thematic analysis in psychology. Qual Res Psycho/2006, 3(2):77-101.

35. Mohiuddin S, Dawani N: Knowledge, attitude and practice of infection control measures among dental practitioners in public setup of Karachi, Pakistan: cross-sectional survey. J Dow Univ Health Sci 2015, 9(1):3-8.

36. Rehman $\mathrm{K}$, Ayaz $\mathrm{H}$, Urooj W: Work-related musculoskeletal disorders among dental practitioners in Khyber Pakhtunkhwa. Pak Oral Dent J 2013, 33(3):531-534.

37. Ibiyemi O, Taiwo JO, Oke GA: Dental education in the rural community: a Nigerian experience. Rural Remote Health 2013, 13(2):2241. 
38. Abbott P, Burgess K, Wang E, Kim K: Analysis of dentists' participation in continuing professional development courses from 2001-2006. Open Dent J 2010, 4:179-184.

39. Gambhir RS, Dhaliwal JS, Anand S, Bhardwaj A: Knowledge and awareness of Consumer Protection Act among private dentists in Tricity, Punjab. J Family Med Prim Care 2015, 4(3):347-351.

40. Bridgman A, Collier A, Cunningham J, Doyal L, Gibbons D, King J: Teaching and assessing ethics and law in the dental curriculum. Br Dent J 1999, 187(4):217-219.

41. Cruess RL, Cruess SR: Teaching professionalism: general principles. Med Teach 2006, 28(3):205208.

\section{Figures}

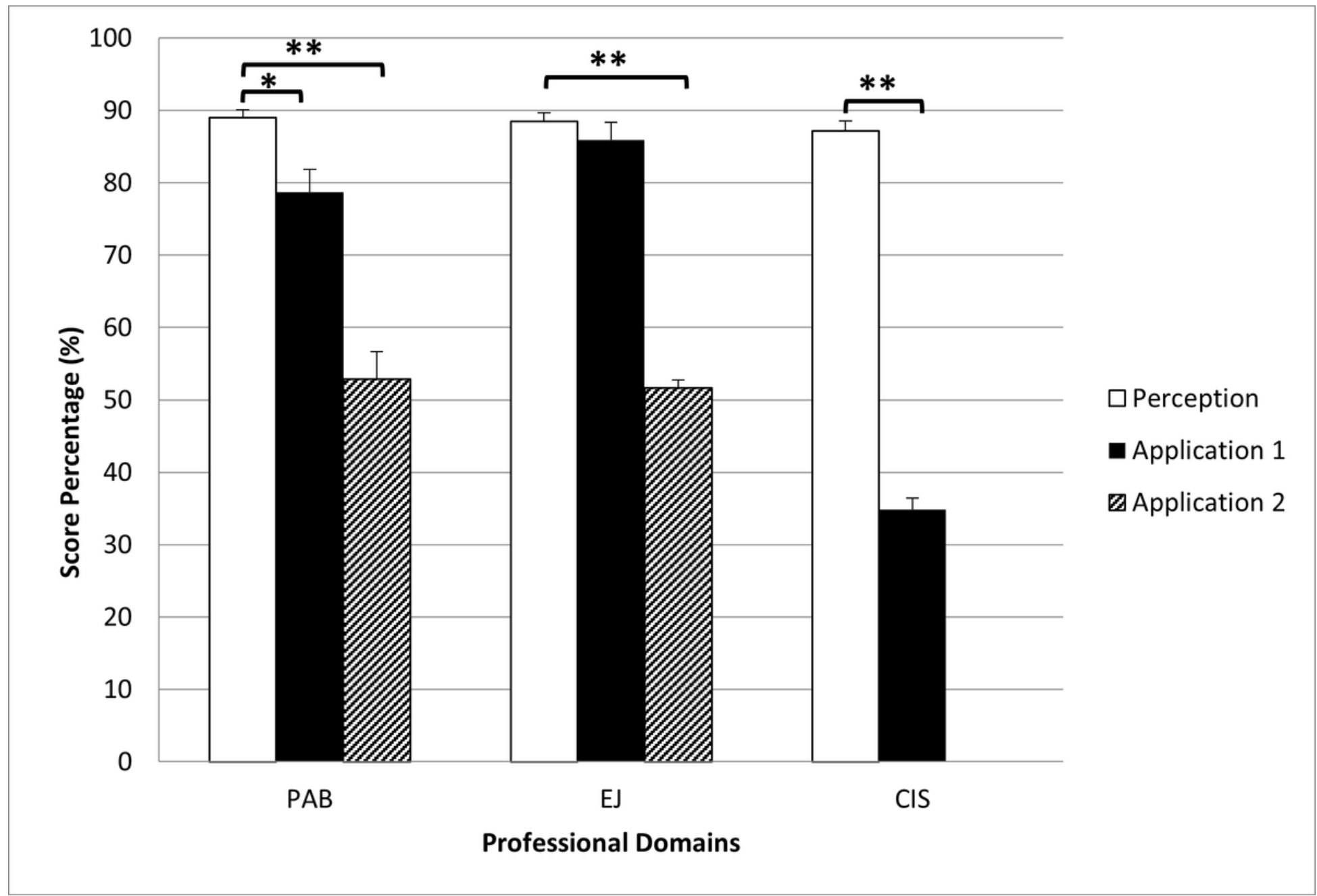

Figure 1

Differences between the mean survey scores (perception) of the three professional domains (PAB, EJ, and $\mathrm{CIS}$ ) and their relevant response scores (applications $1 \& 2$ ) to the clinical video scenarios. $\mathrm{PAB}=$ Professional Attitude and Behaviour, EJ= Ethics and Jurisprudence, and CIS= Communication and 
Interpersonal Skills, applications 1 \& $2=$ relevant questions to the domains, error bars $=+1$ standard error. Significant difference between survey scores, error bars $=+1$ standard error. ${ }^{*}=(p<0.05),{ }^{\star}=(p<0.01)$.

\section{Supplementary Files}

This is a list of supplementary files associated with this preprint. Click to download.

- Appendices.docx 